\title{
Efecto de asepsia y fitohormonas en el establecimiento in vitro de Berberidopsis corallina, a partir de segmentos nodales
}

\author{
Effect of asepsis and phytohormones on the in vitro establishment \\ of Berberidopsis corallina from nodal segments
}

\author{
Matilde E Uribe ${ }^{\mathrm{a}}$, Catherine Delaveau ${ }^{\mathrm{a}}$, Marcelo Garcés ${ }^{\mathrm{a}}$, René Escobar ${ }^{\mathrm{b}}$

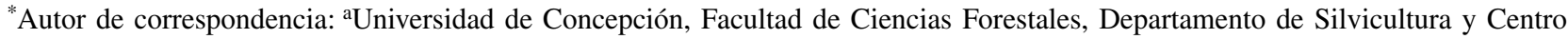 \\ de Biotecnología, casilla 160-C, Concepción, Chile, tel: 41-2204254, fax: 41-2207310, muribe@udec.cl \\ bUniversidad de Concepción, Facultad de Ciencias Forestales, Departamento de Silvicultura, Concepción, Chile.
}

\begin{abstract}
SUMMARY
In order to establish a protocol for the in vitro propagation of Berberidopsis corallina (red michay), the micropropagation of this endemic species of the Chilean Coastal Mountains was studied on MS and DKW media using nodal segments as explants source material. Different concentrations and exposure times of the disinfectant ethanol and commercial chlorine were tested. During the establishment phase, although no significant differences were observed between culture media, the DKW $1 / 2$ medium was selected because the microshoots presented greater vigor and better elongation with this medium. During the proliferation stage, the results indicated that to multiply the shoots and stems, the optimal growth regulation concentration were $0.5 \mathrm{mg} \mathrm{L}^{-1}$ and $0.1 \mathrm{mg} \mathrm{L}^{-1}$ of BAP and IBA, respectively. A positive result in caulinary elongation was observed with the addition of $\mathrm{GA}_{3}\left(0.2 \mathrm{mg} \mathrm{L}^{-1}\right)$. Considering these preliminary results, it was demonstrated that the asexual multiplication of red michay is possible, showing that micropropagation is a potential biotechnological tool, useful for conservation of this interesting native species.
\end{abstract}

Key words: auxins, cytokinins, disinfection, gibberellin, Berberidopsis corallina, in vitro propagation.

RESUMEN

Con el propósito de establecer un protocolo de propagación in vitro de Berberidopsis corallina (michay rojo), se estudió la micropropagación de esta especie endémica de la Cordillera de la Costa, sobre los medios MS y DKW, utilizando segmentos nodales como material fuente de explantos. Se evaluaron diferentes concentraciones y tiempos de exposición a los desinfectantes etanol y cloro comercial. En la fase de establecimiento de los explantos, aunque no se observaron diferencias significativas entre los medios de cultivo, se optó por el medio DKW $1 / 2$, dado que los microtallos mostraron mayor vigor y una mejor elongación. En la etapa de proliferación los resultados mostraron que para la multiplicación de brotes y tallos la concentración óptima de reguladores de crecimiento fue de $0,5 \mathrm{mg} \mathrm{L}^{-1}$ y $0,1 \mathrm{mg} \mathrm{L}^{-1}$ de BAP y AIB, respectivamente. Se observaron resultados positivos en la elongación caulinar con la adición de $\mathrm{GA}_{3}\left(0,2 \mathrm{mg} \mathrm{\textrm {L } ^ { - 1 }}\right)$. Sobre la base de estos resultados preliminares, se demostró que es factible la multiplicación de plantas de michay rojo por vía asexual, mostrándose la micropropagación como una potencial herramienta biotecnológica, útil para la conservación de una especie nativa de interés ecológico y paisajístico.

Palabras clave: auxinas, citoquininas, giberelina, Berberidopsis corallina, propagación in vitro.

\section{INTRODUCCIÓN}

Berberidopsis corallina Hook. (michay rojo), arbusto trepador nativo con gran potencial ornamental, presenta excelentes condiciones para jardinería y confección de balai o yepü; este último se utiliza para limpiar impurezas de los cereales mediante el venteo de éstos al aire (Ward 2003, Tacón 2004). Especie endémica de Chile, perteneciente a la familia Berberidopsidaceae y se encuentra en estado de conservación bajo la categoría de "en peligro" de extinción (Benoit 1989, Hechenleitner et al. 2005).

La especie forma parte de los bosques laurifolios de la vertiente occidental de la Cordillera de la Costa entre la VII (provincia de Cauquenes, 4550' S) y X Regiones (provincia de Llanquihue, $41^{\circ} 10^{\prime} \mathrm{S}$ ). La mayoría de los hábitats están cercanos a cursos de agua o sobre suelos con drenaje restringido, aunque algunas subpoblaciones se encuentran en laderas boscosas secas (Rodríguez et al. 1983, San Martín et al. 1998, LeQuesne et al. 2000). En conjunto con otras especies protegidas caracterizan el sector costero del extremo sudoccidental de la VII Región $\left(36^{\circ} 00^{\prime} 43^{\prime \prime} \mathrm{S}\right)$, donde se ha desarrollado una vegetación nativa cuya importancia radica en el hecho de estar constituida por especies florísticas de interés biográfico y sistemático, así como para la conservación y ecoturismo (San Martín et al. 1998).

Solamente una subpoblación se encuentra dentro de un área protegida del Estado y la mayoría crece con vegeta- 
ción remanente sujeta a invasión por plantaciones de Pinus radiata D. Don y Eucalyptus spp., que al envolver a la vegetación nativa, la posiciona a condición de fragmento, y por colonización desplaza a la vegetación natural (Muñoz 1973, San Martín et al. 1998). El pastoreo por parte de ganado vacuno también ha causado un daño considerable (Hechenleitner et al. 2005).

La producción abundante de frutos en su hábitat natural es rara, por tanto, la reproducción vía semillas es escasa y con respecto a la reproducción vegetativa existen pocos antecedentes (Hechenleitner et al. 2005). Es por ello que la propagación in vitro es una alternativa factible cuando existe dificultad para propagar la especie por métodos agámicos convencionales (Santelices 1994). Hay que destacar que en la literatura no existen trabajos sobre cultivo de tejidos de michay rojo, por lo cual se deben investigar diferentes opciones para su reproducción y por ende para su conservación.

En este trabajo se propone una técnica de propagación vegetativa para rescatar esta especie amenazada, cuyas poblaciones son muy reducidas. Destacar además que el cultivo de tejidos es una vía excelente para incrementar de forma rápida el número de individuos, siendo una etapa importante para el establecimiento de un banco de germoplasma de michay rojo; lo anterior tiene un gran valor no sólo para la investigación, sino también para preservar una especie en peligro de extinción.

\section{MÉTODOS}

Como material vegetal inicial se utilizaron plántulas obtenidas a partir de semillas germinadas y mantenidas durante tres años en vivero, donadas por Forestal y Agrícola Monteáguila. Éstas fueron sometidas a un tratamiento en una solución fungicida (Benomilo y Mancozeb, 10 $\mathrm{g} \mathrm{L}^{-1}$ ) en dos fases de siete días cada una. Transcurrido este periodo se procedió a escindir ramas laterales de las plántulas, a las cuales se les eliminó las hojas a nivel del pecíolo, y se sometieron a un baño en agua corriente durante cinco minutos; luego se realizó una inmersión en una solución fungicida (Captan 2,5 $\mathrm{g} \mathrm{L}^{-1}$ ) durante tres minutos, seguida de un triple enjuague en agua destilada estéril y, posteriormente, se cortaron segmentos nodales de 1,5-2,0 cm de longitud.

A continuación, bajo cámara de flujo laminar y en agitación continua, se inició la asepsia superficial de los explantos mediante una inmersión en etanol al $70 \%$ (v/v) durante 30 segundos, seguido de un lavado en agua destilada estéril por dos minutos. Luego fueron inmersos en una solución de cloro comercial al $50 \%$ (v/v) más dos gotas de detergente, durante 15 minutos (asepsia 1, cuadro 1). Posteriormente se efectuaron cuatro lavados consecutivos en agua destilada estéril durante 2, 5, 15 y 20 minutos, respectivamente (Uribe y Cifuentes 2004). Finalmente, los explantos fueron sembrados en recipientes de vidrio conteniendo $30 \mathrm{~mL}$ de medio de cultivo y se incubaron en cámara de crecimiento a $25 \pm 2{ }^{\circ} \mathrm{C}, 55 \%$ de humedad relativa, bajo un fotoperiodo de 16 horas de luz fría y a una intensidad lumínica de 3.000 lux, por un periodo de 45 días.

Cuadro 1. Concentraciones y tiempos de exposición a los desinfectantes en segmentos nodales de michay rojo.

Concentrations and exposure times of red michay nodal segments to disinfectant.

\begin{tabular}{ccccc}
\hline \multirow{2}{*}{$\begin{array}{c}\text { Número de } \\
\text { asepsias }\end{array}$} & \multicolumn{2}{c}{ Etanol } & \multicolumn{2}{c}{ Cloro comercial } \\
\cline { 2 - 5 } & $\%(\mathrm{v} / \mathrm{v})$ & Minutos & $\%(\mathrm{v} / \mathrm{v})$ & Minutos \\
\hline 1 & 70 & 0,5 & 50 & 15 \\
2 & 50 & 15,0 & 20 & 5 \\
3 & 35 & 1,0 & 20 & 5 \\
4 & 20 & 3,0 & 20 & 5 \\
5 & 35 & 5,0 & 25 & 5 \\
6 & 35 & 5,0 & 30 & 5 \\
\hline
\end{tabular}

En la etapa de establecimiento se emplearon los medios de cultivo DKW (Driver y Kuniyuki 1984) y MS (Murashige y Skoog 1962), suplementados con sacarosa como fuente de carbono (30 $\mathrm{g} \mathrm{L}^{-1}$ ) en ausencia de hormonas (medio base). El pH de los medios de cultivo se ajustó a 5,8 y finalmente se adicionó 0,8\% de agar bacteriológico como agente gelificante. Al final del periodo se compararon los medios de cultivo para determinar diferencias entre ellos y se evaluó el porcentaje de explantos viables, contaminados y muertos. Debido a que en esta etapa se registró necrosis de los explantos, se procedió a optimizar la asepsia variando las concentraciones de alcohol y cloro, y el tiempo de permanencia de los explantos en alcohol (asepsia 2 a 6 , cuadro 1). Por otro lado, se realizó una dilución de los macronutrientes de los medios de cultivo utilizados, DKW a la mitad (1/2) y MS a un cuarto (1/4); se evaluaron al final del periodo los parámetros antes señalados.

Se incubó un total de 200 explantos y la unidad experimental para cada uno de los tratamientos consistió en grupos de dos explantos por recipiente, con un mínimo de seis y un máximo de 12 repeticiones.

En la fase de proliferación los microtallos fueron cultivados en el medio DKW1/2, elegido en la etapa anterior, suplementado con dos combinaciones de citoquinina (bencilaminopurina, BAP 1,0 y $0,5 \mathrm{mg} \mathrm{L}^{-1}$ ), manteniendo una concentración constante de auxina (ácido indolbutírico, AIB 0,1 mg L ${ }^{-1}$ ). Al término de 45 días de cultivo se analizó la acción de los reguladores del crecimiento sobre la elongación y desarrollo de los brotes, y se evaluaron las siguientes variables: número de yemas por explantos, longitud de los brotes y número de hojas por brote.

Por último, los microtallos generados fueron trasplantados a medio base suplementado con dos concentraciones de 
giberelina ( $\mathrm{GA}_{3} 0,1$ y $0,2 \mathrm{mg} \mathrm{L}^{-1}$, medio de elongación), y después de 45 días de cultivo se cuantificó la longitud de los explantos.

En cada recipiente se cultivaron cuatro explantos, los cuales fueron incubados en cámara de crecimiento en las condiciones indicadas previamente.

El tratamiento estadístico de los datos en la fase de establecimiento se realizó con la ayuda del programa estadístico StatMost utilizando planilla Excel. El análisis de las variables cualitativas fue realizado mediante estadística descriptiva, evaluando el porcentaje de supervivencia de los segmentos nodales, en las distintas asepsias y medios de cultivo.

En la etapa de proliferación las variables cuantitativas número de yemas, longitud y número de hojas por explanto fueron analizadas mediante pruebas $\mathrm{F}$ de Fischer y $\mathrm{t}$ de Student. Por efecto del análisis entre la comparación de dos tratamientos $\mathrm{y}$, dada la condición de homogeneidad entre éstos (condiciones dadas), se asumió una distribución normal para el análisis de varianza. Dado el bajo número de réplicas (cinco repeticiones) y cuando éstas no cumplieron los supuestos para la aplicación del análisis de varianza, se aplicó la prueba no paramétrica de Mann-Whitney $(P<0,05)$. Los tratamientos evaluados fueron:

$\mathrm{T}_{1}$ : medio $\mathrm{DKW}^{1} / 2+\mathrm{BAP}\left(1,0 \mathrm{mg} \mathrm{L}^{-1}\right)+\mathrm{AIB}\left(0,1 \mathrm{mg} \mathrm{L}^{-1}\right)$. $\mathrm{T}_{2}$ : medio $\mathrm{DKW}^{1} / 2+\operatorname{BAP}\left(0,5 \mathrm{mg} \mathrm{L}^{-1}\right)+\mathrm{AIB}\left(0,1 \mathrm{mg} \mathrm{L}^{-1}\right)$. $\mathrm{T}_{3}$ : medio DKW $1 / 2+\mathrm{GA}_{3}\left(0,1 \mathrm{mg} \mathrm{L}^{-1}\right)$.

$\mathrm{T}_{4}$ : medio $\mathrm{DKW}^{1 / 2}+\mathrm{GA}_{3}\left(0,2 \mathrm{mg} \mathrm{L}^{-1}\right)$.

\section{RESULTADOS}

La elevada concentración de los desinfectantes y el tiempo de acción del cloro comercial durante la asepsia 1 (cuadro 1) registraron un $100 \%$ de muerte por necrosis de los tejidos (cuadro 2); sin embargo, no hubo presencia de contaminación fúngica o bacteriana.

Cuadro 2. Porcentaje de supervivencia de segmentos nodales de michay rojo después de 45 días de cultivo en medio base MS y DKW*.

Survival percentage of nodal segments of red michay after 45 days of culture in MS and DKW base media.

\begin{tabular}{ccccccccr}
\hline & \multicolumn{4}{c}{$\mathrm{N}^{\circ}$ explantos } & \multicolumn{3}{c}{$\begin{array}{c}\text { Supervivencia } \\
(\%)\end{array}$} \\
\cline { 2 - 7 } Asepsias & Contaminados & \multicolumn{2}{c}{ Muertos } & \multicolumn{2}{c}{ Sanos } & \multicolumn{2}{c}{$(\%)$} \\
\cline { 2 - 7 } & MS & DKW & MS & DKW & MS & DKW & MS & DKW \\
\hline 1 & 0 & 0 & 22 & 24 & 0 & 0 & 0,0 & 0,0 \\
2 & 8 & 7 & 6 & 6 & 4 & 5 & 22,2 & 27,7 \\
3 & 7 & 5 & 5 & 6 & 4 & 5 & 25,0 & 31,3 \\
4 & 6 & 4 & 2 & 3 & 4 & 5 & 28,6 & 41,7 \\
5 & 6 & 5 & 4 & 3 & 6 & 8 & 37,5 & 50,0 \\
6 & 3 & 0 & 1 & 0 & 9 & 13 & 69,2 & 100,0 \\
\hline
\end{tabular}

* Medios de cultivo: DKW (Driver y Kuniyuki 1984) y MS (Murashige y Skoog 1962).

Asepsia 1: medios de cultivo MS y DKW con macronutrientes totales. Asepsias 2-6: MS1/4 y DKW¹/2.
El único tratamiento que permitió obtener porcentajes elevados de explantos asépticos fue la inmersión de los segmentos nodales en etanol $35 \%(\mathrm{v} / \mathrm{v})$ durante cinco minutos y luego en cloro comercial $30 \%$ (v/v) durante cinco minutos (cuadro 1, asepsia 6), obteniéndose entre 69 y $100 \%$ de supervivencia de explantos (cuadro 2). Ésta se vio afectada principalmente por contaminación fúngica, la cual prevaleció ante la contaminación bacteriana.

El análisis estadístico de los datos indica que no hubo interacción medio de cultivo-viabilidad de los explantos, pero arrojó diferencia significativa entre asepsia y viabilidad de los explantos (figura 1), siendo la asepsia 6 la que permitió eliminar por completo los microorganismos y mantener el explanto en buenas condiciones, aun cuando los mejores resultados de supervivencia se obtuvieron en DKW $1 / 2$ (cuadro 2).

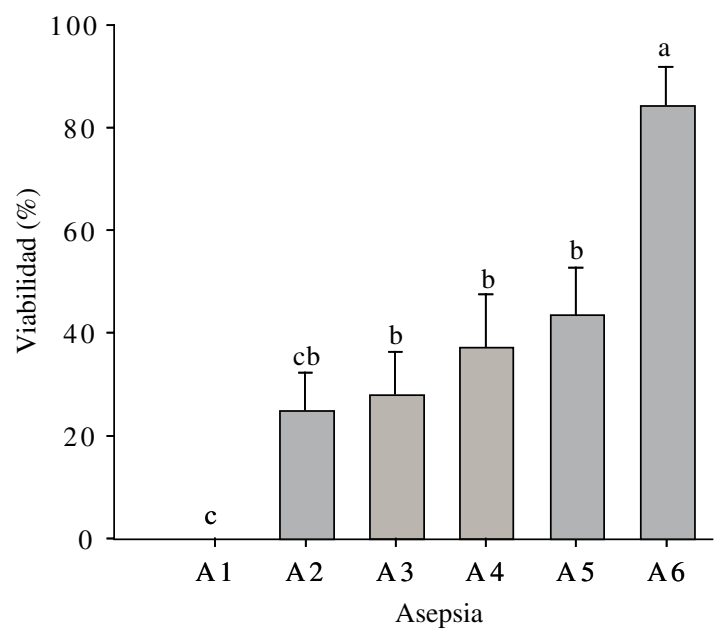

Figura 1. Relación viabilidad-asepsia de los explantos de michay rojo en medios de cultivo MS y DKW. Letras distintas indican diferencias significativas $(P<0,05)$.

Asepsis-viability relationship of the explants of red michay on MS and DKW culture media. Different letters indicate significant differences $(P<0,05)$.

La dilución de los medios de cultivo permitió disminuir la pérdida de explantos por necrosis de los tejidos, aunque siempre los mejores resultados se obtuvieron en $\mathrm{DKW}^{1} \mathbf{2}$ (cuadro 2). Por otro lado, al analizar visualmente la longitud y desarrollo de los explantos viables, no se observaron grandes diferencias entre los medios de cultivo probados. No obstante, se eligió $\mathrm{DKW}^{1} \mathrm{1} / 2$ para la fase posterior de proliferación in vitro de michay rojo, debido a que produjo microtallos de mayor vigor y de mayor longitud (figura 2A y B).

En relación al número de yemas por microtallo, el análisis estadístico indica que hubo diferencias significativas con respecto a los dos niveles hormonales de citoquininas empleados, obteniéndose el mayor número de yemas estimuladas por explanto con la combinación 


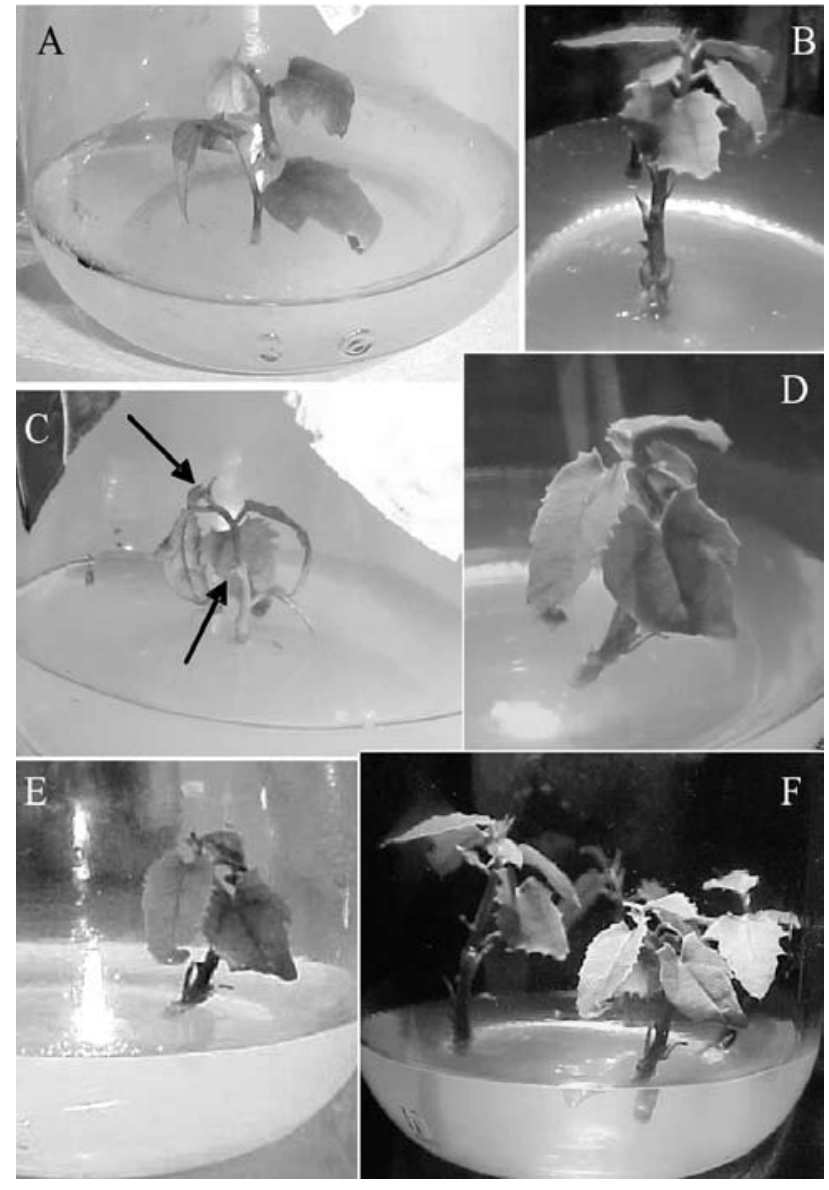

Figura 2. Micropropagación de segmentos nodales de Berberidopsis corallina después de 45 días de cultivo. A) Microtallos en fase de establecimiento en medio MS $1 / 4$ libre de hormonas. B) Microtallos en fase de establecimiento en medio DKW $1 / 2$ libre de hormonas. C) Microtallos en medio de proliferación DKW $1 \frac{1}{2}$ BAP/AIB $\left(0,5 / 0,1 \mathrm{mg} \mathrm{L}^{-1}\right)$. Flecha señala la aparición de nuevos puntos de crecimiento que darán origen a nuevos brotes. D) Incremento en el número de hojas por explanto en medio DKW112. E) Elongación caulinar de microtallos en medio DKW $1 / 2$ suplementado con $\mathrm{GA}_{3}$ $0,1 \mathrm{mg} \mathrm{L}^{-1}$. F) Elongación caulinar de microtallos en medio DKW1/2 suplementado con $\mathrm{GA}_{3} 0,2 \mathrm{mg} \mathrm{\textrm {L } ^ { - 1 }}$.

Micropropagation of Berberidopsis corallina nodal segments, after 45 days of culture. A) Microshoots establishment stage on $\mathrm{MS}^{1 / 4}$ medium free from hormones. B) Microshoots establishment stage on $\mathrm{DKW}^{1} 1 \frac{2}{2}$ medium, free from hormones. C) Microshoots on proliferation medium DKW $1 \frac{1}{2} \mathrm{BAP} / \mathrm{IBA}\left(0.5 / 0.1 \mathrm{mg} \mathrm{L}^{-1}\right)$. Arrow indicates new growth points that will become new sprouts. D) Increase in the number of new leaves per explant in DKW $1 / 2$ medium. E) Caulinary elongation of microshoots in DKW $1 / 2$ medium supplemented with $\mathrm{GA}_{3} 0.1 \mathrm{mg} \mathrm{L}^{-1}$. F) Caulinary elongation of microshoots in $\mathrm{DKW}^{1} / 2$ medium supplemented with $\mathrm{GA}_{3} 0.2 \mathrm{mg} \mathrm{L}^{-1}$.

hormonal correspondiente al tratamiento $\mathrm{T}_{2}(0,5 / 0,1 \mathrm{mg}$ $\mathrm{L}^{-1}$ ) de BAP/AIB (cuadro 3). Esto implica una mayor estimulación de brotes preformados (figura $2 \mathrm{C}$ ) generado por la citoquinina y una mejor elongación y manifestación de estos puntos de crecimiento.
Cuadro 3. Efecto de las hormonas sobre el desarrollo y proliferación de microtallos de michay rojo (medias por explanto $\pm \mathrm{ES}$ ).

Effect of hormones on development and proliferation of red michay microshoots. The values represent the mean \pm SE. Different letters indicate significant differences.

\begin{tabular}{cccc}
\hline $\begin{array}{c}\text { Concentración } \\
\text { BAP/AIB (mg L }\end{array}$ & $\mathrm{N}^{\mathrm{o}}$ yemas & $\mathrm{N}^{\mathrm{o}}$ hojas & Altura $(\mathrm{mm})$ \\
\hline $1,0 / 0,1$ & $1,79 \pm 0,33 \mathrm{~b}$ & $3,1 \pm 0,54 \mathrm{a}$ & $4,6 \pm 0,24 \mathrm{~b}$ \\
$0,5 / 0,1$ & $3,79 \pm 0,26 \mathrm{a}$ & $2,8 \pm 0,51 \mathrm{~b}$ & $6,0 \pm 0,33 \mathrm{a}$ \\
\hline
\end{tabular}

Letras distintas indican diferencias significativas $(P<0,05)$.

En la etapa de proliferación se observó un aumento paulatino de las respuestas, a medida que transcurrió el tiempo de cultivo, entre las cuales se acentuó la aparición de hojas. En este sentido, los resultados muestran que el número promedio de hojas por explanto fue afectado por el tratamiento hormonal, siendo el tratamiento $\mathrm{T}_{1}$ estadísticamente mayor $\left(1,0 / 0,1 \mathrm{mg} \mathrm{L}^{-1}\right.$ de BAP/AIB) (cuadro 3, figura 2D).

Sin embargo, el desarrollo en longitud de los microtallos se vio afectado por el tratamiento hormonal empleado, observándose diferencias significativas entre las dos concentraciones de citoquininas analizadas, apreciándose que la concentración $0,5 / 0,1 \mathrm{mg} \mathrm{L}^{-1}$ de BAP/AIB se presentó como la más adecuada (cuadro 3 ).

La estimulación de los entrenudos bajo las dos concentraciones de ácido giberélico empleadas permitió un mayor desarrollo de los explantos, aunque no hubo diferencias significativas entre los tratamientos. Sin embargo, se aprecia que los explantos en presencia de $\mathrm{GA}_{3} 0,2 \mathrm{mg} \mathrm{L}^{-1}$ desarrollaron un mayor crecimiento en longitud $(22 \mathrm{~mm})$.

\section{DISCUSIÓN}

Durante la etapa de establecimiento, y de acuerdo a los resultados obtenidos, el factor limitante en la supervivencia y viabilidad de los explantos es el tratamiento de asepsia aplicado, así como también la concentración salina de los medios de cultivo (cuadro 2). El pardeamiento total de los explantos evidencia el efecto tóxico de los desinfectantes. Este efecto se ha reportado para otras especies, dado que el empleo de dosis elevadas de agentes desinfectantes elimina la microbiota contaminante pero causa la muerte de todos los explantos utilizados (Alvarado 1998). En consecuencia, se confirma la importancia de la condición de asepsia en la técnica de cultivo de tejidos, puesto que una determinada técnica no siempre es la más adecuada dado que dependerá de la especie en estudio.

Por otra parte, la presencia de contaminación en explantos en los tratamientos usados y en ambos medios de cultivo pone en evidencia que ésta se relaciona con el estado fitosanitario de la planta donante. Sin embargo, la aplicación 
de fungicida a la planta madre ha permitido incrementar la eficiencia de esta fase. De acuerdo a Cassells (1991), los contaminantes en el cultivo de tejidos pueden causar grandes pérdidas en los procesos de propagación in vitro. De ahí la importancia de su eliminación desde la fase de establecimiento, donde los daños son menores debido al menor volumen de explantos que se manipulan. Esto confirma lo señalado por Alvarado (1998), quien expone que en la lucha por prevenir o eliminar la contaminación en el cultivo in vitro se ensayan y ponen en práctica diferentes opciones que van desde el incremento de las medidas de asepsia, tratamientos de las plantas donantes, hasta la utilización de productos antimicrobianos de origen sintético o natural, entre otros.

El medio MS presenta un contenido fuerte de nitrógeno (60 meq $\mathrm{L}^{-1}$ ), mientras que el medio DKW presenta una menor concentración (51 meq $\left.\mathrm{L}^{-1}\right)$. En consecuencia, la supervivencia y viabilidad de los explantos también podrían estar afectadas por la concentración salina de los medios de cultivo, ya que los medios ricos en nitrógeno pueden favorecer la necrosis de los tejidos (Margara 1988). De esta manera, al diluir los medios de cultivo en este estudio se favorece el desarrollo y vigor de los explantos, pues éstos estaban más saludables, con hojas más verdes y expandidas. Bajo estas condiciones, siempre las mejores respuestas se presentan en medio $\mathrm{DKW}^{1 / 2}$ (cuadro 2, figura $2 \mathrm{~A}$ y B). Estos resultados concuerdan con los encontrados por Muñoz (2000) en Castanea sativa Mill., quien utilizó ambos medios de cultivo con macronutrientes diluidos a la mitad, obteniendo mejores resultados en el medio DKW12/2. Sin embargo, meristemos foliares de diferentes especies de Salix cultivados en medio MS con concentraciones de nutrientes al $100 \%, 50 \%$ y $25 \%$, permiten determinar que las concentraciones de nutrientes al $100 \%$ y $50 \%$ muestran un mejor desarrollo de los explantos, existiendo escasa diferencia entre ellas (Chung y Carrasco 1998). En este sentido, la nutrición mineral in vitro depende, a la vez, de elementos proporcionados por el explante y de los aportados por la solución nutritiva. Es decir, la nutrición mineral depende de las dimensiones del explanto, de la naturaleza de los tejidos, de la actividad metabólica, de la frecuencia de los trasplantes y de la composición del medio (Margara 1988, Pierik 1990). Por otro lado, Donoso (1998) hace hincapié en que la condición fisiológica de la planta donante tiene una marcada influencia sobre la respuesta in vitro, probablemente como resultado de su interacción con la disponibilidad de nutrientes, niveles endógenos de los reguladores de crecimiento y los principales aminoácidos libres, cuyas proporciones y cantidades varían en las distintas épocas del año.

En relación con la estimulación de yemas preformadas durante la etapa de proliferación (cuadro 3), es posible destacar que los resultados logrados concuerdan con los obtenidos en Gevuina avellana Mol., dado que en esta especie, a medida que la concentración hormonal disminuye, el número de brotes aumenta (Mardones 1999).
Similares resultados fueron obtenidos por Martínez-Pastur y Arena $(1995,1996)$ en Nothofagus obliqua (Mirb.) Oerst. y Nothofagus nervosa (Phil.) Krasser, en la micropropagación de luma del norte (Legrandia concinna (Philippi) Kausel.) (Uribe y Cifuentes 2004) y en embriones aislados de N. nervosa (Sánchez-Olate et al. 2004), donde las mejores respuestas en la tasa de multiplicación se alcanzaron a bajas concentraciones de citoquinina.

Al respecto, Orellana (1998) señala que el balance auxinas-citoquininas es determinante en el coeficiente de multiplicación, por lo que al lograr un balance adecuado es posible alcanzar elevadas tasas de proliferación, aumentando la efectividad del método de micropropagación. Según Vieitez y Vieitez (1982), a concentraciones de 1 ó 2 $\mathrm{mg} \mathrm{L}^{-1}$ de BAP se obtiene el mayor número de brotes en material juvenil, no obstante los microtallos no elongan, produciéndose arrosetamiento de los explantos, por lo que concluyeron que la concentración óptima para la proliferación se encuentra entre $0,1-0,5 \mathrm{mg} \mathrm{L}^{-1}$ de BAP y que la multiplicación de brotes en medio carente de BAP es prácticamente nula. Sin embargo, Pierik (1990) indica que los requerimientos de citoquininas (tipo y concentración de citoquinina) son extremadamente variables y dependen del contenido endógeno de cada especie.

Es conocido que las hojas se originan como resultado de una serie de divisiones celulares periclinales en los flancos del meristemo apical y su desarrollo está bajo control de citoquininas y auxinas principalmente. De esta manera, los resultados obtenidos en este estudio (cuadro 3, figura 2D) indican que concentraciones superiores de citoquininas permiten aumentar significativamente el número de hojas por explanto, a lo largo del cultivo in vitro. Esto coincide con los resultados obtenidos por Mundaca (2001) en estudios realizados en belloto del sur (Beilschmiedia berteroana (Gay) Kosterm.) donde se observa un mejor desarrollo de hojas en concentraciones superiores de citoquinina.

Calderón-Baltierra et al. (1993), en estudios realizados en Gomortega keule (Mol.) Baillon., observaron que a medida que incrementan los días de cultivo se obtiene una alta producción de hojas por frasco. Similares resultados fueron obtenidos en G. avellana por Mardones (1999), quien señala que el número de verticilos aumenta a medida que se incrementa el tiempo de permanencia de los microtallos en la cámara de cultivo.

La elongación de los brotes de michay rojo no es óptima con los tratamientos hormonales ensayados (cuadro 3). Esto concuerda con lo señalado por Calderón-Baltierra (1994), dado que la mayor elongación que presentan los microtallos corresponde al medio que contiene una menor concentración de citoquininas, logrando con esto disminuir la división celular y promover la elongación del tejido debido a la acción de las auxinas.

Según Talón (1993), la aplicación exógena de giberelina produce una amplia variedad de respuestas en el desarrollo. La inducción del crecimiento del tallo es, probablemente, el efecto fisiológico más importante de este regulador, 
sobre todo en variedades de plantas enanas y en roseta. Por tanto, una de las razones de aplicar exógenamente $\mathrm{GA}_{3}$ en uno de los ensayos, es precisamente producir la elongación de los entrenudos. Al respecto, se encontró que el alargamiento es significativamente superior en ambas concentraciones utilizadas comparado con los tratamientos en ausencia de ésta. En este sentido, los resultados obtenidos se pueden relacionar con investigaciones similares hechas en Eucalyptus globulus Labill. por CalderónBaltierra (1994), quien concluye que concentraciones de $\mathrm{GA}_{3}$ inferiores a $0,5 \mathrm{mg} \mathrm{L}^{-1}$ permiten el alargamiento de brotes adventicios sin producir deformación foliar en combinación con tratamientos de oscuridad por periodos cortos. En contraste, Chung y Carrasco (1998), en estudios de cultivo in vitro de varias especies de Salix, utilizando la aplicación exógena de tres concentraciones de $\mathrm{GA}_{3}$ $\left(0,1 ; 0,5\right.$ y $\left.1,0 \mathrm{mg} \mathrm{L}^{-1}\right)$ en presencia o ausencia de BAP, determinan que los mejores resultados se obtienen con la mayor concentración de $\mathrm{GA}_{3}\left(1,0 \mathrm{mg} \mathrm{L}^{-1}\right)$ en presencia de $0,1 \mathrm{mg} \mathrm{L}^{-1}$ de $\mathrm{BAP}$, permitiendo un desarrollo rápido $\mathrm{y}$ vigoroso en un $76 \%$ de las distintas procedencias de las especies estudiadas.

El método utilizado demostró ser exitoso, con resultados que permiten pensar que se ha logrado así un efectivo método para micropropagar y clonar material juvenil de esta especie. Por otra parte, el cultivo de tejidos de michay rojo in vitro supera notablemente la dificultad de producir masivamente plantas a partir de semilla, ofreciendo una vía alternativa y adecuada para clonar y preservar esta especie mediante la técnica sugerida en esta investigación. Además, estudios futuros a través de la vía de organogénesis indirecta permitirán masificar la producción de brotes adventicios y, por consiguiente, la obtención de plantas completas luego de definir un protocolo de enraizamiento con fines de obtener germoplasma suficiente para estudios de diversidad genética.

\section{CONCLUSIONES}

La desinfección de las plantas madres es indispensable para disminuir la contaminación en la fase de establecimiento del material vegetal. La inmersión de los segmentos nodales en etanol $35 \%(\mathrm{v} / \mathrm{v})$ durante cinco minutos $\mathrm{y}$ luego en cloro comercial $30 \%$ (v/v) durante cinco minutos (asepsia 6), resultó ser el tratamiento más eficiente en el control de la contaminación sin afectar la viabilidad de los explantos.

El cultivo in vitro de Berberidopsis corallina a partir de segmentos nodales es posible en medio DKW con macronutrientes diluidos a la mitad, suplementado con $0,5 / 0,1$ (mg L $\left.{ }^{-1}\right)$ de BAP/AIB, respectivamente. La elongación caulinar es mayor en presencia de $\mathrm{GA}_{3} 0,2\left(\mathrm{mg} \mathrm{L}^{-1}\right)$, pero requiere de una optimización con estudios más acabados. Se hace hincapié que estos resultados fueron obtenidos en plantas juveniles provenientes de vivero $\mathrm{y}$, por otro lado, que se requiere estudiar tratamientos que incluyan la etapa de enraizamiento.

\section{AGRADECIMIENTOS}

Estudio financiado por Universidad de Concepción, Proyecto DIUC N ${ }^{\circ}$ 203.412.003-1.0. Los autores agradecen al Dr. Carlos LeQuesne (CONAF, Universidad Austral de Chile) y a Forestal y Agrícola Monteáguila (Los Ángeles) por proveer el material vegetal utilizado en este estudio. A la Dra. Darcy Ríos L. (Facultad de Ciencias Forestales, Universidad de Concepción) por su incondicional apoyo científico a lo largo de esta investigación. A los M.Sc. Víctor Jara S. y Sixto Martínez (Unidad Académica Los Ángeles, Universidad de Concepción), por su colaboración en el análisis de los resultados.

\section{REFERENCIAS}

Alvarado Y. 1998. Contaminación microbiana en el cultivo in vitro de plantas. In Pérez JN ed. Propagación y mejora genética de plantas por biotecnología. Instituto de Biotecnología de las Plantas, Cuba. p. 81-104.

Benoit C. 1989. Libro rojo de la flora terrestre de Chile. Santiago, Chile. Ministerio de Agricultura. 157 p.

Calderón-Baltierra X, F Pérez, A Rotella. 1993. Micropropagación de una especie chilena "en peligro" de extinción: Gomortega keule (Mol.) Baillon (Magnoliopsidae, Gomortegaceae). Bosque 14(1): 23-28.

Calderón-Baltierra X. 1994. Influencia del calcio y ácido giberélico en el alargamiento de brotes adventicios in vitro de Eucalyptus globulus. Bosque 15(1): 33-38.

Cassells AC. 1991. Problems in tissue culture: culture contamination. In Debergh P, RH Zimmerman eds. Micropropagation. Dordrecht, The Netherland. Kluwer Acad. Publish. p. 31-45.

Chung G, G Carrasco. 1998. Micropropagación de Salix spp. a través de meristemos foliares. Instituto Forestal Chile. Ciencia e Investigación 12(1): 63-77.

Donoso I. 1998. Desarrollo de técnicas de cultivo in vitro de bayas de vid. Memoria Ingeniero Agrónomo. Santiago, Chile. Facultad de Ciencias Agrarias y Forestales, Escuela de Agronomía, Universidad de Chile. 73 p.

Driver D, A Kuniyuki. 1984. In vitro propagation of Paradox Walnut Rootstock. HortScience 19: 507-509.

Hechenleitner VP, MF Gardner, PI Thomas, C Echeverría, B Escobar, P Brownless, C Martínez. 2005. Plantas amenazadas del centro-sur de Chile. Distribución, conservación y propagación. Primera Edición. Valdivia, Chile. Universidad Austral de Chile y Real Jardín Botánico de Edimburgo. $188 \mathrm{p}$.

LeQuesne C, R Carrasco, L Sandoval. 2000. Lista de puntos florísticos de algunas especies en peligro, raras y vulnerables en la Región del Bío-Bío. CONAF-Chile. Serie Técnica Año 3(4): 1-16.

Mardones L. 1999. Recuperación de genotipos de avellano chileno (Gevuina avellana Mol.), mediante cultivo in vitro de em- 
briones. Memoria de Título Ingeniero Forestal. Concepción, Chile. Facultad de Ciencias Forestales, Universidad de Concepción. $40 \mathrm{p}$.

Margara J. 1988. Multiplicación vegetativa y cultivo in vitro. Los meristemos y la organogénesis. Madrid, España. Ediciones Mundi-Prensa. 232 p.

Martínez-Pastur G, M Arena. 1995. In vitro propagation of Nothofagus obliqua (Fagaceae). Aust. J. Bot. 43: 601-607.

Martínez-Pastur G, M Arena. 1996. In vitro propagation of Nothofagus nervosa (Phil.) Dim. et Mil. Phyton 58: 1-7.

Mundaca P. 2001. Micropropagación in vitro de Belloto del Sur (Beilschmiedia berteroana (Gay) Kostermans. Seminario de Título Ingeniero (E) Forestal. Los Ángeles, Chile. Depto. Forestal. Unidad Académica Los Ángeles, Universidad de Concepción. 34 p.

Muñoz C. 1973. Chile: plantas en extinción. Santiago, Chile. Universitaria. $127 \mathrm{p}$.

Muñoz M. 2000. Multiplicación in vitro de clones selectos de Castanea sativa Mill. Memoria de Título Ingeniero Forestal. Concepción, Chile. Facultad de Ciencias Forestales, Universidad de Concepción. 39 p.

Murashige T, F Skoog. 1962. A revised medium for rapid growth and bioassays with tobacco tissue cultures. Physiol. Plant. 15: 473-497.

Orellana P. 1998. Introducción a la propagación masiva. In Pérez JN ed. Propagación y mejora genética de plantas por biotecnología. Instituto de Biotecnología de las Plantas, Cuba. p. 125-132.

Pierik R. 1990. Cultivo in vitro de plantas superiores. Ediciones Mundi-Prensa. Madrid, España. 301 p.
Rodríguez R, O Matthei, M Quezada. 1983. Flora arbórea de Chile. Concepción, Chile. Ed. Universidad de Concepción. $407 \mathrm{p}$.

Sánchez-Olate M, D Ríos, M Pedraza, G Pereira, H Castellanos, $\mathrm{R}$ Escobar. 2004. Propagación in vitro de Nothofagus procera ((Poepp. et Endl.) Oerst.) a partir de embriones aislados. Bosque 25(1): 123-128.

San Martín J, T Yáñez, J Loyola. 1998. Plantas trepadoras. Universidad de Talca. Consultado el 25 de abril 2002. Disponible en: http://arbol.tripod.cl/3.htm.

Santelices R. 1994. Propagación vegetativa de algunas especies nativas chilenas. Informe Interno. Santiago, Chile. Facultad de Ciencias Agrarias y Forestales, Universidad de Chile. $37 \mathrm{p}$.

Tacón A. 2004. Manual de productos forestales no madereros. Programa de fomento para la conservación de tierras privadas de la Décima Región. Valdivia, Chile. CIPMA. 22 p.

Talón M. 1993. Giberelinas. In Azcon-Bieto J, M Talón eds. Fisiología y Bioquímica Vegetal. Madrid, España. McGrawHill/Interamericana. p. 301-318.

Uribe ME, L Cifuentes. 2004. Aplicación de técnicas de cultivo in vitro en la propagación de Legrandia concinna. Bosque 25(1): 129-135.

Vieitez AM, ML Vieitez. 1982. Castanea sativa plantlet proliferated from axilary buds cultivated in vitro. Scientia Horticulturae 18: 343-351.

Ward D. 2003. Una mirada antropológica hacia el mundo del artesano del Voqui Fuco en un contexto de desarrollo sostenible. Departamento de Antropología, Universidad de Chile. Revista Mad N ${ }^{\circ} 9.69$ p. 